Technological University Dublin

DÜBLIN

ARROW@TU Dublin

\title{
Festival Connections: People, Place and Social Capital
}

\author{
Bernadette Quinn \\ Technological University Dublin, bernadette.quinn@tudublin.ie
}

Follow this and additional works at: https://arrow.tudublin.ie/tfschhmtbook

Part of the Human Geography Commons, Other Social and Behavioral Sciences Commons, and the Sociology Commons

\section{Recommended Citation}

Quinn, B. \& Wilks, L. (2013) Festival connections: people, place and social capital, in Richards, G., de Brito, M.P. \& Wilks, L. (Eds) Exploring the Social Impacts of Events, pp. 15 - 30, Oxon: Routledge

This Book Chapter is brought to you for free and open access by the School of Tourism \& Hospitality Management at ARROW@TU Dublin. It has been accepted for inclusion in Books / Book chapters by an authorized administrator of ARROW@TU Dublin. For more information, please contact arrow.admin@tudublin.ie, aisling.coyne@tudublin.ie,gerard.connolly@tudublin.ie.

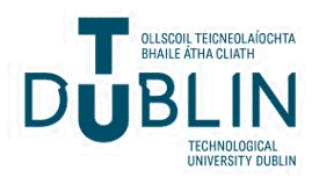


Citation: Quinn, B. \& Wilks, L. (2013) Festival connections: people, place and social capital, in Richards, G., de Brito, M.P. \& Wilks, L. (Eds) Exploring the Social Impacts of Events, pp. 15 - 30, Oxon: Routledge

\section{Introduction}

Festivals are premised on social interaction. The word 'festival' derives from the Latin 'festum', meaning feast (Isar 1976), and collective, participatory celebration is central to its meaning. To date, while some researchers have investigated the nature of social inter-relationships evident in festival settings, the literature on the social dimensions of festival activity is under-developed. While Deery and Jago (2010) suggest that social impact literature in particular has come of age, it can be argued that in general, the literature on social connections in festival settings is quite disparate and uneven in terms of disciplinary underpinnings, theoretical references, research questions and methodological approaches. Acknowledgement of these difficulties has prompted some researchers to search for alternative theoretical frameworks to underpin a comprehensive enquiry into social connections in festival settings. Social capital is starting to emerge as a theory which shows real potential. Drawing on the findings of two exploratory studies, one in Ireland and one in England, this paper considers the diverse sets of social relationships at the heart of festival activity, whilst taking account of the role that place plays in these interactions.

\section{Social capital and festivals}

The potential that social capital offers to further understanding of the formation, nature and implications of social connections between various actors in festival settings is becoming increasingly realised by researchers. Writing in the wider event context, Misener and Mason (2006) advocated using social capital as a theoretical framework within which to investigate how events contribute to community development. Suggesting a move away from thinking about how events impact upon society, they envisage that the theoretical lens of social capital offers significant opportunity to unravel the complexity of relationships and power dynamics that characterise communities. Specifically in festival contexts, social capital has already been used by Wilks (2011) as a theoretical framework to investigate festival attendees. Arcodia and Whitford (2007) have also explicitly explored the synergies between social capital and festivals, again in the context of festival attendees. 
Focusing on festival attendance only, they argue that festival attendance builds social capital by developing community resources, promoting social cohesion and by giving an opportunity for public celebration. They identify a range of further research questions worth posing in respect of festival audiences. In contrast, Finkel (2010) approaches the topic from the perspective of community residents, producing empirical findings supporting the assertion that festivals can be a mechanism for strengthening communities through providing opportunities for shared, collective action and experiences. Mykletun (2009), meanwhile, approaches the problem from the perspective of festival organisers: investigating the workings of a number of forms of capital, including social capital, in a festival in Norway. Although studies which explicitly link social capital and arts festivals are rare, there is some exploration in the literature of linkages between social capital and the arts (Dowling, 2008) as well as a number of studies which link social capital to broader leisure activities (Arai \& Pedlar, 2003; Blackshaw \& Long, 2005).

Thus, recently an increasing interest in social capital and festivals is evident. Festival researchers are drawing on ideas from different social capital theorists and the focus is widening to incorporate the formation and development of social capital within and across an increasing breadth of festival actors or stakeholder groups. It is also beginning to focus more on the role that place may play in the formation of social capital.

\section{Social capital theory}

At the outset, it must be acknowledged that social capital is a complicated and contested concept with differing interpretations of its meaning and usefulness. Two of the leading theorists are Putnam and Coleman. Putnam (1995, 2000) emphasises networks, norms and social trust, with co-operation and collaboration producing mutual benefits for individuals, including a sense of well-being. His twin concepts of bridging social capital, that is, the promotion of links between diverse individuals; and bonding social capital, that is the increase in solidarity between homogeneous groups, were identified as particularly useful by Wilks (2011) as a framework for her study of three music festivals.

Coleman (1988) focuses on 'the structure of relations between actors and among actors' and on the facilitation of 'certain actions of actors within the structure' (1988, p. S98). He therefore sees social capital as being lodged within the structure, or 
network, rather than in the individual, and also considers social capital to be linked to the provision of economic and non-economic resources which allow the achievement of interests. Coleman asserts that social organisation is strongly related to economic activity, particularly in a 'closed' network, such as a close-knit place-based or tradebased community. He also highlights the role of family and community in the establishment of norms that both inhibit crime and act to ensure that trustworthiness is taken for granted. Therefore, according to Coleman, social capital embedded in networks is a public good which benefits all who are part of such a structure, rather than primarily benefiting the person or persons whose efforts may be necessary to bring it about. Although Coleman's approach to social capital is less prominent in the festivals literature, it has potential to underpin a study of festival settings and their associated social networks of stakeholders.

\section{Social capital, festivals and place}

Place has long been of interest to festival researchers because festivals are a key mechanism through which people continuously make and re-make collective identities and connections with place. Closely allied to the notion of identity are concepts like pride in place, kinship and community, all of which are connected to social capital. The role that festivals play in reproducing connections with place is complicated. If they have been noted for their role in perpetuating and reproducing norms and traditions (Lavenda, 1997; Ekman, 1999) they have equally been found to reproduce space in ways that alter or sometimes disrupt local ways of living in, and connecting with, place (Boyle \& Hughes, 1994; Misener \& Mason, 2006). Consistently, researchers have noted how festivals are socially constructed, never impromptu or improvised (Waterman, 1998) but rather are social practices where dominant meanings are promoted, negotiated and sometimes strongly resisted. Festival spaces, then, are never neutral, and can be characterised by absence as well as presence, resistance as well as acceptance, inclusion as well as exclusion. The specificities of particular places results in them affording different potentials for forming and developing different types of social capital. This is an assertion that has been considered by a number of researchers, but usually in a way that is more implicit than explicit in its references to social capital theories, and one that remains underdeveloped (Curtis, 2010; Quinn, 2005, 2006; Sharpe, 2008). While certain areas of study, notably economic geography, have long used the concept of social capital to 
debate the influence of place on, for example, the successful development of various enterprises, this has not been the case in the study of festivals. Indeed, when researchers have specifically focused on forms of capital in discussion of festivals or related areas like tourism, the formative role of place is rarely explicitly considered although it may be captured to some extent in references to, for example, physical capital or nature capital (Mykletun 2009).

\section{Framing the empirical study}

Thus it can be suggested that there is a need to broaden enquiries away from measuring social impact to a more holistic investigation into the kinds of social connections built up in the course of festival activity. However, while a growing interest in studying the links between festival and social capital is becoming clear, much remains to be done in terms of determining the most appropriate aspects of social capital theories to apply to the study of festivals. There is a need to identify the key hallmarks and manifestations of social capital development and to explain its development. In many of the studies reviewed above, social capital is understood to take a number of forms, and festivals are posited as acting as catalysts for developing some or all of these forms. Furthermore, there is a need to broaden any conceptual framework to incorporate the breadth of actors involved: not simply attendees or volunteers but also for example, performers, organisers, employees, volunteers and business owners. The fact that these actors usually emanate from both within and beyond the immediate locale of the festival opens up the possibility of investigating the spatial dimension of social capital. This is infrequently researched (Rutten, Westlund and Boekema 2010).

The over-arching research question investigated in this study was therefore: 'How does social capital operate amongst the range of actors within the place-based festival setting?' As a first step in framing the empirical investigation, the festival landscape was modelled to highlight the various places that social actors might occupy (see Figure 1). 


\section{Hinterland Zone}

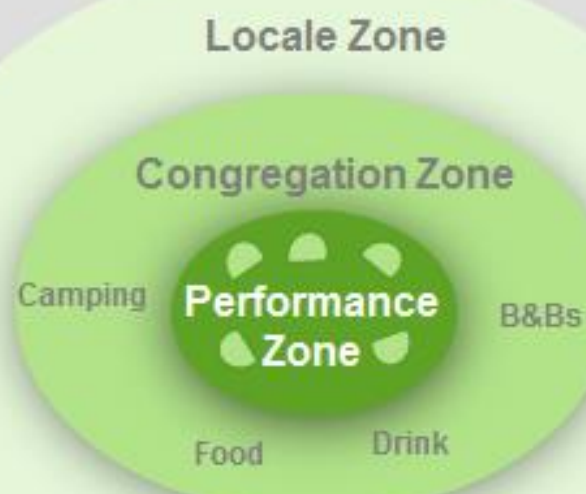

= stage

Figure 1: Zoning the festival landscape

In this model, the festival event itself may be seen as the nucleus. When viewed from a place-based perspective, the performance spaces, including 'stages' and the 'auditoria', could be regarded as the core; around this could be placed the festival spaces where audiences congregate when not directly consuming performance, such as accommodation or refreshment venues; beyond this is the festival locale, whether urban or rural; whilst further beyond still is the festival's wider geographical setting, the hinterland.

Within each of these zones are situated festival actors or stakeholders, who have varying degrees of involvement (or non-involvement) with the festival (see figure 2). 'Involved' actors may include audiences, performers, organisers, sponsors, hoteliers, caterers, and so on. Some of these may have dual or multiple roles. 'Non-involved' actors may be people who live or work in the festival locale, along with a myriad of people in the festival's geographical hinterland. The empirical investigations reported here look at the extent to which the festival created a series of interactions and interrelationships within and across these zones, linking together places, and the multitude of actors located within these places. 
Cultural businesses

Stall holders
Policy makers

Sponsors

\section{Festival organisers}

\section{Artists}

\section{Audiences \\ Local residents}

Media

Local businesses

Non-attending residents

Figure 2: Zoning the festival actors

\section{Methodology}

The two exploratory case studies examined here were selected for their apparent place embeddedness, although the nature of the links with place differed quite considerably. The Waterside festival in Milton Keynes, England is a community festival with sizeable local audiences, as well as some visitors, a sizeable local volunteer content, and sizeable local input in terms of staging, performance, hospitality and so on. The Tradfest festival in Dublin, Ireland is also rooted in place. It is relatively more high profile in terms of its tourism-orientation, budget, sponsorship arrangements and performer profiles. However it was held in a specific district within the city; was clearly intended to raise the profile of that district; was organised by the local traders association and; drew upon the district's services to stage the event and host participants. It furthermore showcased traditional Irish music to attract visitors and to strengthen the district's association with this cultural form.

In order to explore the various components of social capital amongst the range of festival-related groups of actors a qualitative approach was used. Festival organisers, volunteers, performers, venue managers, traders, as well as audiences were purposively targeted. A series of brief 'in-the-moment' interviews were conducted with participants as the festival was in progress. A semi-structured approach was used 
to direct the interviews, all of which were recorded. Twenty-one interviews were recorded at the Waterside festival and twenty-two at Tradfest, ranging from 5 minutes to 18 minutes in length. These were transcribed, then content analysed using NVivo.

\section{Findings}

Taking a lead from the identified theories, a number of themes were identified using the interview texts as evidence. For the purpose of this paper, the theme highlighted for discussion is the myriad of connections identified both between and across categories of social actors. The connections to place, articulated in terms of pride in place and place identity are briefly discussed.

\section{Connecting people}

Connections between sets of social actors were highlighted by several of the participants at both festivals. These connections were often 'bonding' with already known friends or family, but people also 'bridged' to other categories of social actor. WP11 highlighted the role of family links at Waterside, for example, with the festival acting as a focal point for drawing in relatives from further afield:

R1: What do you get out of the festival?

WP11: Just family time, basically. I get family coming down from where I used to live up in Grimsby, and they come down for the weekend and just sit and relax, listen to music with the family. So it's really good fun.

Bonding with friends was also highlighted by WP11, as well as by other participants, including WP3,

R1: Yes, ok. And what about friends, have you got any friends round about?

WP11: Friends hanging about. The one who's sat here is, I work with him, so I just come over but I usually get a few friends from work and that come down and that as well. .... so it is really a family-and-friends affair.

The Tradfest findings were similar. Many people in the audience had come in a pair. Two sisters in the 60s were a good example:

R2: So can I ask you why did you come to the concert today?

TF2: My sister is into traditional music and she said to me would I like to come so...

R2: Okay so you've come with your sister. 
TF2: Yeah I've come with her.....

R2: And have you travelled to come today?

TF3: No I just came from Dublin.

R2: Alright.

TF3: My sister came from Wicklow.

Five Dutch visitors in their 20s had flown into Dublin for the festival specifically to see a particular artist but also to meet up with friends:

R2: So do you five spend a lot of time together normally?

TF6: Well we live in Copenhagen and they live in Holland so.....

$\mathrm{R} 2$ : Ah so this is a good opportunity to catch up.

TF6: Yeah.

In both festivals, while several respondents noted the general sociability prevailing, neither settings were particularly notable for the opportunity to make new friends. At Waterside, WP3 and WP11 were cases in point:

R1: $\quad$ So is it people you know already, then? Or do you, kind of, meet new people here?

WP3: They're just people I know already.

WP11 also stressed that, for him, while being generally friendly and sociable, the Waterside event was not about making new friends:

R1: $\quad$ Do you meet any new people at all?

WP11: You, no - you talk, do you know what I mean? You can talk to people but I wouldn't really say I meet anyone to see again - I mean you speak to them, they're sat near, you can talk to them, but I don't really get to meet friends, you know what I mean, new friends, or-

The findings at Tradfest were broadly similar although there were some indications that the potential at least, for forming new friendships, existed. TF1, for example, was a young woman with a small baby had recently moved to Dublin from Canada:

TF1: I came to listen to exciting music and to get out of the house a bit with the little one and have an excuse.

R2: And do you know any of the people in the audience?

TF1: No I don't. 
R2: Okay, and have you been chatting to people?

TF1: I have, especially today.

R2: Oh right, okay.

TF1: Probably with the baby. Some people have recognised me and oh you're back again and the person sitting next to me sat next to me yesterday so we talked a bit.

A young Dutch visitor, who had travelled as part of a group was another example of someone who had made new friendship connections:

R2: And have you met many new people since you've come here? Have you made any new friends?

TF7: Well I met him so (laughs) (another member of the Dutch group). It's my first time and we met some girls from Norway.

At Waterside, despite little or no evidence of enduring links being built between individuals, the festival was seen as an inclusive place where people tended to get on with each other, as highlighted by an unemployed black youth:

WP16: So when you walk up to a place like this, it's good because you get away from what you're used to and that. Like this, it only happens once a year and that, so it's a bit of a change, it's a bit different, like. As well as that, yeah, it's for one day within the year, yeah, that so many different stereotypes, that can get along....

A volunteer on car park duty at Waterside, WP14, also commented on the sense of inclusion:

WP14: I mean everybody - if you just look around the park, I think you do see so many different people, old people and all, yeah?

R1: And what do you think the people are like here, as well. Do you get an impression of what kind of people are here?

WP14: Mixed, really, it's a bit of everyone.

Somewhat similarly, the Tradfest somehow communicated a sense of inclusiveness and belonging in a way that reflected a sense of what it is like to live in Dublin more generally. One audience member, a Londoner visiting her daughter who had moved to live in Dublin spoke as follows:

R2: So your link to Dublin is just that your daughter is here.

TF11: It is and she loves it and I keep thinking oh it would be nice for her to come home and she says "this is home mum and I love Dublin". 
R2: How long is she here now?

TF11: Five years.

R2: Okay.

TF11: And she loves it and you know when everybody talks about oh, there was a couple of men sitting in the concert with Ralph McTell and they were Irish and they said why on earth would anybody come to Dublin? Well we said well we don't know why you would leave it, you know. Quite strange.

As well as connections being built within sets of social actors, like audience members, there was evidence that connections were being made between different sets of actors. At Tradfest, for example, it was clear that performers were using the 'stage' of the festival to network and connect with influential actors in the media, music and festival world more widely. Equally, they were actively seeking to raise their profile with consumers. A discussion with two young performers makes this clear:

R2: What I want to know is: you are performers, so what do you get out of tonight? TF12: It's very good PR just to get a showcase in the Dublin area.

R2: Okay.

TF12: It's very good to get exposure and it's a new sort of crowd that I wouldn't normally play to, you know.

R2: So would you not get into this kind of Dublin area much?

TF12: No, no not really....

R2: So do you feel you're going to benefit tonight?

TF13: Oh yeah definitely, yeah. Oh absolutely yeah.

R2: And sell some...

TF13: Yeah sold a few CD's and got a few (business) cards and stuff so that's great.

Another conversation with a more experienced solo musician reiterated the point:

R2: So have you met people, have you...?

TF14: Yes oh I have. I met a guy from Holland there and various people.

R2: And what kind like?

TF14: A radio presenter from Holland. A few people who asked me about lessons for their children. People like who are willing to drive from Dublin to Waterford for lessons like the thing and you know so it's really good. 
In both of these instances, the connections being made extended far beyond the festival locale. Two of these three performers had travelled from elsewhere in Ireland to perform. Foreign media professionals were present, so too were artistic directors from other traditional music festivals both in Ireland on the continent. In several cases, audience members had flown into Dublin specifically to attend the festival. Indeed, several of the volunteers and two of the interns working with the festival organisation had specifically come to Dublin to advance their music / festival / event industry career aspirations. A closer reading of the data than is possible here reveals the highly mobile, fluid and internationally connected circuit of flows that make up the world of festivals. Meanwhile, at the more localised Waterside festival, the links being fostered between attendees and local organisations, such as the Scouts, and local schools, were highlighted, with the festival being seen as a good place to raise profile and awareness of the organisations and create pathways for new and enduring links to be forged:

R1: So what do you yourself get out of the festival, do you think?

WP21: Hopefully an awareness of, we're a Scout group, hopefully an awareness of the Scout Group and also to raise some funds as well, for the Scout Group.

Similarly, a stall holder with local Milton Keynes charity, the LIONS ('Living In Our Neighbours' Service') was keen to use Waterside as a route to making useful new connections through talking to people, rather than as a social occasion:

R1: $\quad$ So you don't see it as a place to, I don't know, make new friends-

WP7: It isn't for that purpose, no. We do have our advertising leaflet that tells people about our club, and if anybody here expresses an interest, we try to persuade them to join us.

The local organisations were also seen as pathways at Waterside for encouraging attendance at the festival:

WP9: Both of the schools get directly involved, you know, so they were both singing yesterday, I think they're both doing maypole-dancing today, or certainly the primary school is. And so, and the children from those schools almost inevitably the vast majority of them will come and participate in the festival. Like my daughter did, because they're local children and it's their festival. 
The Parks Trust, which owns the land on which the festival takes place also used a stall at the event, staffed by intern, WP15, to raise awareness of their role:

WP15: Well, this is all our land so we're here to, sort of, promote ourselves with various activities, we're promoting things that are upcoming and we're also here, sort of, to keep an eye on things. We've also, we helped set up all the parking and stuff - so we're just here because it's our land, just to, a presence, really.

Connections between the many volunteers who helped to make the Waterside festival happen were evident. Also connections made between volunteers and attendees, and between volunteers and members of the wider community, including stall holders, charities, security personnel and police offices during the process of organising the festival demonstrate the role of the festival within its local setting as a conduit for social networks. Committee member WP9 highlighted the benefits of the social network:

R1: $\quad$ So what do you yourself get out of the festival?

WP9: I think it's nice working with a group of people towards a common aim. And it's nice seeing the result of that work over a period of time.

The hope that volunteering for the Parks Trust may lead to links to future employers beyond the festival was also expressed by WP15:

R1: Is that to get experience for a job or something, really?

WP15: Yeah, well, I came out of a Master's last August so since then I haven't had any, much, work - so I think you need to volunteer to get experience.

At Tradfest, there were strong signs that young volunteers were determinedly using the festival for networking purposes. TF5 and TF15, two young Dutch students made this clear:

R2: Okay and you got involved really soon after arriving?

TF5: Yeah because a friend of mine who studied with me in the Netherlands she worked for the Temple Bar Traders so she knew about the festival and she connected us to them as volunteers.

R2: So are there a lot of you Dutch females volunteering?

TF5: Yeah well we are. As far as I know around five people 
R2: And have you made some new friends from volunteering or do you expect that you might?

TF5: I expect yeah because the girls seem to be very nice. I just got to know them today.

R2: And why have you been interested to volunteer?

TF15: Actually because I moved to Dublin Thursday (laughs).

R2: (Laughs) from?

TF15: From Holland and I'm doing my thesis over here and to maybe start up some network and get to know some people, you know, you never know.

R2: Okay and is that why you have volunteered to network?

TF15: Yeah, yeah and to get to know the city, you know, Temple Bar cultural area and my study is international leisure management so I'm very interested in culture.

\section{Connecting to place}

At Waterside, the sense of attachment to the locale was very evident. As the following dialogue makes clear, there was a strong sense that the festival 'fitted' and benefited the place:

R1: $\quad$ So do you think this festival is good for Great Linford?

WP3: Very good for Great Linford.

R1: $\quad$ Yeah. In what way?

WP3: It's, I don't know, it's just in the Manor, innit? Do you know what I mean? The Manor's beautiful. Milton Keynes doesn't have much history, and to put a festival in the manor is the best thing for the manor, isn't it? And this, we're behind this property you see around you, and the land, I should imagine loads of functions happened throughout the years, whatever, 600 years they've been here. I should imagine they've had loads of events[...]It's carrying it on in a modern age, isn't it? Which I think's brilliant.

Another participant also expressed appreciation for the role of the festival in highlighting the local place:

WP11: Oh, cause it just shows what people, what a community can do. I know it's not just a community thing but it's in Great Linford and people look at it as a Great Linford Waterside Festival because it shows Great Linford up as a good place to be, a lovely area. 
A strong sense was gained that the Waterside festival attracted people from the local area: the 'festival locale' in terms of the model proposed above:

R1: $\quad$ Do you live locally, then?

WP11: Yeah, just round the corner. It's walking distance, yeah, not far, it's right on our doorstep.

R1: $\quad$ So do you live round here yourself?

WP9: Yep, I live about 100 yards away.

Also, making the connection between the festival and place, as well as hinting at a desire to assert belonging to the local area, WP6 suggested that location was a key feature in her decision to attend:

WP6: Well, it's the first time I've ever been and I guess 'cause we've, we just moved here a year ago, I thought it would be nice to do something in the actual area that we lived, so.

At Tradfest, the situation was quite different. A lot of the actors involved were Dubliners, but they had little routine association with the area, and so the sense of the 'local' as evidenced at Waterside was quite different. Temple Bar proved to be a district that several respondents including audience members, performers and volunteers did not know very well. The effect of the festival was to introduce participants to parts of the city with which they were not familiar with, for various reasons. Thus the festival was actively building a positive sense of place for the district. Most obviously, however, the festival was found to be generating a sense of pride in, and appreciation of, traditional music, and by extension, the place of Ireland. For Irish people, there was a sense of pride in the 'quality' of the tradition that was being revealed to them. Equally, there was a pride in the fact that the festival was giving foreigners an opportunity to appreciate Irish traditional culture. The opinions expressed below were not unique:

R2: Who has contributed to this festival? What have you noticed? 
TF4: ... and here you can see you have the old and the young and you have, well I don't know whether they're visitors or maybe people who have immigrated into the country and they really appreciate our culture and I think maybe, maybe sometimes we don't promote our culture which we should do.

TF17: I think it's great for visitors, you know, we're renowned for our culture and our music and to actually see it this close and this live and you know such a good quality of, you know, musicians. Like you can hear music in lots of places, you know, in the evening time. They're not so much what you'd consider professionals, well they wouldn't sell the way, you know, you'd like it to be so I like to think that these people are going home, especially visitors with a certain, you know, a certain...........

R2: Oh right, okay. So what do you think of the festival then? What's your sense of it so far? Who benefits from it?

TF 2: I think it's wonderful. I've never been to the festival here before but this is a beautiful hall and I think the acoustics was fantastic. I'd never been in here before.

R2: And are you from Dublin?

TF2: I am would you believe (laughs). I have never, I've passed it many times, you know, but I've never been in before.

R2: Would you say that it enhanced your enjoyment of the concert?

TF2: Yes it would have, it would have done.

R2: Can you talk to me about that?

TF2: I just think that as I said the acoustics was fantastic and the surroundings so old if you like and that it just, I just felt that it was a kind of, it was music that you liked, it was traditional in a traditional setting if you like for the want of a word and as I say sometimes halls like these don't lend themselves to ballads and I think it's wonderful and I'll come again. And downstairs I will bring people to come and visit downstairs and see Dublin.

\section{Conclusions}

A clear sense that a festival setting is a place which enables connections to be made was gained from the empirical data collected at the two festival case studies analysed here. It seemed that bonding social capital was prevalent amongst family and friendship groups, whilst bridging social capital was generated between the different 
sets of social actors. The geographical place of the festival was identified as a key feature in anchoring the inter-connections and providing a sense of community. Trust and well-being were identified as prevalent and could be said to be important in providing a feel-good backdrop which meant that social actors were more open to the formation of both bonding and bridging social capital. Trust is partly rooted in place, in that social actors had a sense of sharing norms and values by having chosen to attend the event, either due to local connections or, in the case of Tradfest to a felt connection to the cultural tradition. In these case studies it seemed that Coleman's (1988) approach to social capital, which stresses the role of the network in enabling the formation of social capital, as well as linking it to economic benefit, is most appropriate. However, Putnam's (2000) bridging and bonding social capitals are also of value. Although bridging social capital was not identified within the sets of social actors, it seems that bridging social capital may be a useful aid to understanding the economic benefits gained by social actors who bridge across social actor sets.

\section{References}

Arai, S., \& Pedlar, A. (2003). Moving beyond individualism in leisure theory: a critical analysis of concepts of community and social engagement. Leisure Studies, 22, 185-202.

Arcodia, C., \& Whitford, M. (2007). Festival Attendance and the Development of Social Capital. Journal of Convention \& Event Tourism, 8(2), 1 - 18.

Belfiore, E., \& Bennett, O. (2007). Rethinking the social impacts of the arts International Journal of Cultural Policy, 13(2), 135 - 151.

Blackshaw, T., \& Long, J. (2005). What's the big idea? A critical exploration of the concept of social capital and its incorporation into leisure policy discourse. Leisure Studies, 24(3), 239-258.

Boyle, M., \& Hughes, C. G. (1994). The politics of urban entrepreneurialism in Glasgow. Geoforum, 25(4), 453-470.

Coleman, J. S. (1988). Social capital in the creation of human capital. The American Journal of Sociology, 94 (Supplement: Organisations and Institutions: Sociological and Economic Approaches to the Analysis of Social Structure), S95 - S120. 
Crespi-Vallbona, M., \& Richards, G. (2007). The meaning of cultural festivals. International Journal of Cultural Policy, 13(1), 103-122.

Curtis, R. A. (2010). Australia's capital of jazz? The (re)creation of place, music and community at the Wangaratta Jazz Festival. Australian Geographer, 41(1), 101-116.

De Bres, K., \& Davis, J. (2001). Celebrating group and place identity: a case study of a new regional festival. Tourism Geographies, 3(3), 326-337.

Deery, M., \& Jago, L. (2010). Social impacts of events and the role of anti-social behaviour. International Journal of Event and Festival Managemen, 1(1), 828.

Dowling, M. (2008). Fiddling for outcomes: traditional music, social capital, and arts policy in Northern Ireland. International Journal of Cultural Policy, 14(2), $179-194$.

Edwards, B., \& Foley, M. W. (2001). Much Ado about Social Capital. [Article]. Contemporary Sociology, 30(3), 227-230.

Field, J. (2003). Social capital. London: Routledge.

Fine, B. (2001). Social capital versus social theory: political economy and social science at the turn of the millenium. London: Routledge.

Finkel, R. (2010). "Dancing Around the Ring of Fire": Social Capital, Tourism Resistance, and Gender Dichotomies at up Helly Aa in Lerwick, Shetland. Event Management, 14(4), 275-285.

Foley, M. W., \& Edwards, B. (1999). Is it time to disinvest in social capital? Journal of Public Policy, 19(2), 141-173.

Galloway, S. (2009). Theory-based evaluation and the social impact of the arts. Cultural Trends, 18(2), 125 - 148.

Healey, T. (2004). Social capital: old hat or new insight? Irish Journal of Sociology, $13(1), 5-28$.

Holbrook, E. (2011). Behind the Music: How concert and music festival organizers manage the risks of Lollapalooza, Coachella, Burning Man and more. Risk management, 58(5), 18-23.

Long, P., \& Owen, E. (2006). The arts festival sector in Yorkshire: economic, social and cultural benefits, benchmarks and development. Retrieved 13th March 2007 , from 
http://www.artscouncil.org.uk/publications/publication_detail.php?rid=9\&id= 514

Matarasso, F. (1997). Use or ornament? The social impact of participation in the arts. Retrieved 16th March 2006, 2006, from www.comedia.org.uk/pages/pdf/downloads/use_or_ornament.pdf

Merli, P. (2002). Evaluating the social impact of participation in arts activities. A critical review of François Matarasso's Use or ornament? International Journal of Cultural Policy, 8(1), 107-118.

Misener, L., \& Mason, D. (2006). Creating community networks: Can sporting events offer meaningful sources of social capital? Managing Leisure, 11(1), 39-56.

Mykletun, R. J. (2009). Celebration of Extreme Playfulness: Ekstremsportveko at Voss. Scandinavian Journal of Hospitality \& Tourism, 9(2/3), 146-176.

Putnam, R. D. (1995). Bowling alone: America's declining social capital. Journal of Democracy, 6(1), 65 - 78.

Putnam, R. D. (2000). Bowling alone: the collapse and revival of American community. New York: Simon \& Schuster.

Quinn, B. (2005). Arts festivals and the city. Urban Studies, 42(5-6), 927-943.

Quinn, B. (2006). Arts festivals and sustainable development in Ireland. Journal of Sustainable Tourism, 14(3), 288-306.

Reeves, M. (2002, May 2002). Measuring the social and economic impact of the arts: a review. $\quad$ Retrieved 29th May 2006, 2006, from http://www.artscouncil.org.uk/documents/publications/340.pdf

Rutten, , R., Westlund, H. \& Boekema, F. (2010) The spatial dimension of social capital. European Planning Studies, 18(6): 863-871.

Sharpe, E. K. (2008). Festivals and social change: intersections of pleasure and politics at a community music festival. Leisure Sciences, 30(3), 217-234.

Waterman, S. (1998). Carnivals for elites? The cultural politics of arts festivals. Progress in Human Geography, 22(1), 54-74.

Wilks, L. (2009). Initiations, interactions, cognoscenti: social and cultural capital in the music festival experience. Unpublished $\mathrm{PhD}$, The Open University, Milton Keynes.

Wilks, L. (2011). Bridging and bonding: social capital at music festivals. Journal of Policy Research in Tourism, Leisure and Events, 3(3), 281-297. 